Documento / Document

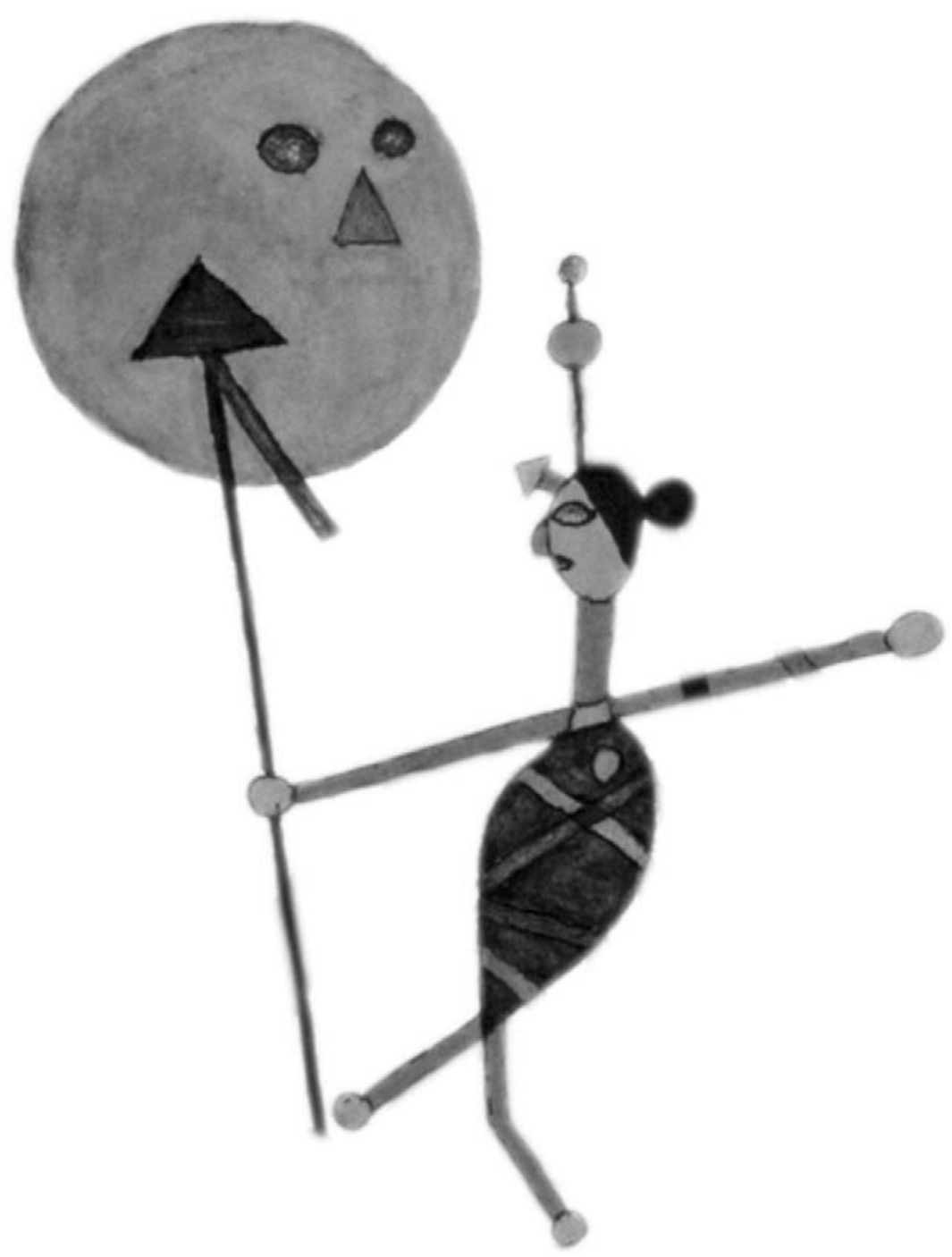




\section{Um visitante inglês na Bahia de 1800}

Jean Marcel Carvalho FRANÇA ${ }^{1}$

RESUMO: Apresentamos aqui, precedido de uma introdução explicativa, o fragmento de uma narrativa de viagem relativa ao Brasil, escrita pelo comerciante inglês John Turnbull em 1805, intitulada A Voyage round the world in the years 1800,1801,1802, 1803 and 1804. Turnbull aportou na Baía de Todos os Santos em agosto de 1800, permanecendo quatro ou cinco dias na cidade. Apesar da brevidade da visita, suas impressões sobre o Brasil trazem, entre outras coisas, curiosas notas sobre a situação de Portugal e de sua rica colônia dos trópicos no então conturbado cenário político europeu.

PALAVRAS-CHAVE: Salvador; navegações; viajantes britânicos.

O historiador José Honório Rodrigues comentou certa vez que os relatos de visitantes estrangeiros sobre o Brasil, depois do desembarque de D. João VI, tornaram-se tão numerosos, que reuni-los e analisá-los sumariamente implicaria escrever um volume à parte do seu História da história do Brasil. Rodrigues, um conhecedor de longa data do assunto, por certo não exagerava. Prova disto é a incorporação, de maneira variada, às vezes com mais, às vezes com menos prudência, de alguns desses relatos ao corpus documental de inúmeros trabalhos acadêmicos produzidos nas últimas décadas. Destarte, ainda que muitas dessas pesquisas lancem mão, num universo de possibilidades bastante variado, quase sempre de uns poucos e repetitivos nomes (Luccock, Debret, Rugendas, Maximiliano, Denis, Spix e Martius, Burton, Ina von Binzer...), não se pode dizer que se trate de um domínio pouco conhecido ou pouco explorado pelos pesquisadores locais. Ao contrário, no que se refere a narrativas xeno-brasileiras oitocentistas - para usarmos uma expressão de A. de E. Taunay ${ }^{3}$ - a historiografia brasileira tem explorado razoavelmente o seu potencial informativo. 
Há, no entanto, no tocante a visitantes estrangeiros, um punhado de anos do século XIX, nomeadamente o período compreendido entre o início do século e o desembarque de D. João VI (1808), que praticamente tem sido esquecido pelos historiadores. É verdade que não são anos pródigos em narrativas de viagens sobre o Brasil. É verdade, também, que as poucas narrativas existentes não primam pela mesma riqueza de informações das suas congêneres posteriores a 1808, quando o visitante, livre para transitar pelas cidades portuárias e mesmo pelo interior do País, esmerava-se em descrever detalhes e detalhes do até então misterioso Brasil. Antes de 1808 a situação era muitíssimo diferente. As autoridades locais, avessas à presença de navios estrangeiros em portos brasileiros, quando eram obrigadas a recebê-los, salvo raríssimas exceções, não somente tratavam de despachá-los o mais rápido possível, como, durante sua permanência, impunham severas restrições aos tripulantes - que podiam desembarcar somente durante o dia, em grupos pequenos e acompanhados por um oficial português.

Ainda que em menor número e mais pobres no que tange à variedade e ao colorido das descrições, esses relatos oitocentistas anteriores a 1808, porém, não deixam de oferecer muita matéria de interesse para o pesquisador. Recordemos, a título de exemplo, quão curiosas são as informações que o capitão Jean-François Landolphe legou-nos sobre a atividade da maçonaria no Rio de Janeiro de $1800^{4}$, quão detalhadas são as descrições feitas pelo inglês Thomas Lindley da cidade de Salvador em $1801^{5}$, ou quão argutas são as observações sobre a sutil transformação que se processava na sociedade carioca de 1803, deixadas pelo também inglês James Kingston Tuckey ${ }^{6}$. E haveria ainda que acrescentar a essa reduzida lista as breves mas instrutivas notas de George Mouat Keith sobre a Bahia em 18057 , a descrição do russo Krusenstern ${ }^{8}$ da Santa Catarina de 1803, e as curiosas observações de James Hardy Vaux (1807) e Thomas O’Neil (1808)9 sobre o Rio de Janeiro - as últimas, a propósito, muito citadas por Oliveira Lima no seu D. João VI no Brasil, são tanto mais interessantes por terem sido escritas por um tenente da marinha inglesa que viajava no London, um dos navios da frota britânica que escoltaram D. João VI de Lisboa para a capital da colônia.

A lista poderia ser ainda alongada um pouco mais com o relato 
do comerciante inglês John Turnbull, autor de um pequeno livro intitulado A Voyage round the world in the years 1800,1801, 1802, 1803 and $1804^{10}$, cujo fragmento relativo ao Brasil traduzimos abaixo. Turnbull aportou na Baía de Todos os Santos em agosto de 1800 e aí permaneceu, como era habitual, por pouco tempo: 4 ou 5 dias somente. Sua narrativa não é de todo inédita em língua portuguesa. Em 1816, três anos depois do lançamento da $2^{\underline{a}}$ edição inglesa da obra, o incansável Hipólito José da Costa, no seu Correio Brazilliense, comentou longamente o relato, chegando inclusive a traduzir alguns trechos. Na ocasião, Costa, sempre empenhado em divulgar as notícias de além-mar que pudessem ser úteis à formação dos seus conterrâneos, assim justificou o interesse pelas nem sempre simpáticas mas liberais opiniões do visitante inglês:

Além da instrução geral que se adquire com a leitura de viajantes, esta tem um interesse particular para os leitores de nosso periódico pela grande parte que o Brasil ocupa nas observações do autor; porquanto, não pode ser indiferente aos habitantes do Brasil as reflexões que fazem as pessoas sensatas, que visitam o seu país, sobre os seus costumes, legislação, comércio, etc.; e tanto mais quanto um estrangeiro pode ver muitos objetos por diferentes faces e melhor do que os naturais, a quem os prejuízos e o hábito, muitas vezes, impedem ver seus próprios defeitos. É verdade que também os prejuízos ou ignorância desses viajantes podem induzi-los a perverter os fatos; mas sempre é bom ouvi-los e refletir sobre o que eles dizem ${ }^{11}$.

Infelizmente, pouco conseguimos apurar sobre esse visitante que, como menciona H. J. da Costa, tanto espaço concedeu ao Brasil nas suas observações - o que era relativamente raro na época. Em sua narrativa, Turnbull apresenta-se como um agente comercial inglês que, com autorização da Companhia das Índias Orientais, em maio de 1800, deixou o porto de Portsmouth a bordo de um navio de nome Margaret, com destino ao Oriente, e acabou por realizar uma viagem de circunavegação. Acerca das razões que o levaram a lançar-se em tão arriscada aventura, o inglês comenta: 
Na qualidade de segundo oficial do Barwell durante a sua última viagem à Índia em 1799, tivemos, eu e o primeiro oficial do navio, depois de algumas observações, razões mais que suficientes para acreditar que os americanos retiram grandes lucros das relações comerciais que mantêm com a região nordeste desse vasto continente. Impressionados com tal constatação, logo que retornamos para casa, tratamos de expô-la a indivíduos entendidos em empresas comerciais. Tais indivíduos convenceram-se do que dizíamos e não perderam tempo em pôr o nosso plano em execução ${ }^{12}$.

Foi em busca dessa lucrativa rota comercial com o nordeste da China que Turnbull, depois de uma rápida ancoragem na ilha da Madeira, passou pela Bahia de Todos os Santos. De tal passagem, como o leitor poderá constatar, para além de algumas observações gerais sobre a cidade e seus habitantes, o aventureiro, como bem destaca Louise Gunther num estudo recente ${ }^{13}$, procura sobretudo chamar a atenção para quão útil seria ao Império Britânico tomar o controle dessa próspera colônia lusa da América Austral; colônia extremamente rica, que os portugueses, povo pusilânime, segundo Turnbull, cedo perderiam para os inimigos da Inglaterra - como fazia antever a enorme influência francesa e espanhola sobre as autoridades locais.

Durante o decorrer da viagem, o vento sul castigou-nos de tal modo que nos vimos obrigados a aproximar-nos 2 graus e meio da costa do Brasil. A passagem pela zona tórrida deu-se de maneira assaz tediosa e o navio, embarcação nova e ainda não aclimatada, passou a vazar por todos os lados. Tais circunstâncias levaram-nos a buscar o porto de São Salvador, onde tencionávamos reparar devidamente a embarcação antes de alcançar as latitudes mais elevadas.

Ao entrarmos no porto, os habitantes começaram a cogitar inúmeras coisas acerca do navio inglês e dos objetivos da sua viagem. Tais cogitações, é bom que se diga, em muito deveram-se à semelhança entre a nossa embarcação e uma brigue cúter. Muitos consideraram que éramos espiões franceses em viagem de reconhecimento dos portos e costa do País; o mais empenhado em espalhar essa notícia era um irlandês mestiço, comandante de um paquete a serviço dos portugueses. A maioria, no entanto, estava certa de que viajávamos numa embarcação de guerra britânica disfarçada de navio mercante, e que tínhamos 
como propósito verificar quantas embarcações espanholas se encontravam no interior do porto e qual o seu poder de fogo.

Os sete capitães espanhóis que então se encontravam na cidade acreditaram piamente nessa última versão. $O$ terror destituiu-os completamente do bom senso, levando-os a pensar que trazíamos 70 ou 80 homens escondidos sob a escotilha, e a evitar as proximidades do nosso navio. Estranha revolução na história das nações: os espanhóis, outrora conhecidos por sua proverbial coragem, agora são conhecidos por sua igualmente proverbial covardia. É, na verdade, o que geralmente ocorre quando uma circunstância qualquer na vida política de uma nação a condena a um longo período de inação. A preguiça consome as energias do caráter nacional e dos caracteres individuais. A coragem e a bravura militar têm necessidade de serem postas em prática, sem o que perdem o vigor e rapidamente deixam de existir.

As cogitações a nosso respeito cedo chegaram aos ouvidos do vice-rei, que imediatamente nos enviou uma mensagem convocandonos a ir ao palácio na manhã seguinte. Nesse meio tempo, um oficial e uma forte guarda militar estacionaram a bordo e, como se isto não bastasse, colocaram um barco patrulha de cada lado do nosso navio. Ficamos, pois, impossibilitados de dar um passo sequer.

Foi-nos permitido, como demonstração de grande indulgência, receber a visita de um dos oficiais do Queen East Indiamen, por meio do qual tomamos conhecimento do triste fado desta embarcação, que pegou fogo próximo à costa, perdendo toda a sua carga e muitas vidas. O oficial ficara em São Salvador com a incumbência de tomar as providências necessárias caso algum dos bens porventura viesse a aparecer. Ao ver, porém, que nada seria recuperado, o oficial tratou de comprar uma passagem para casa numa presa pertencente a um baleeiro ancorado no porto. O único empecilho que ainda o detinha em São Salvador era o medo que tinha o mestre da presa de que, ao deixar o porto, os espanhóis cumprissem as ameaças de represálias que haviam feito. A nossa presença mostrou-se, pois, especialmente auspiciosa para esses dois cavalheiros. Estávamos agora mais do que em pé de igualdade com os espanhóis, os quais, por sua vez, tinham consciência disto e certamente não renovariam suas ameaças.

Em resposta às nossas perguntas acerca da captura da presa, o 
mestre explicou-nos que alinhou com a embarcação na costa do Brasil e começou a caçá-la; os tripulantes espanhóis logo abandonaram o navio e retiraram as riquezas que traziam (37 mil dólares) para uma lancha, que rapidamente seguiu em direção à terra. Atento a toda essa movimentação, o capitão do baleeiro deixou de lado o navio e passou a perseguir a lancha, alcançando-a e compelindo-a, quase sem nenhuma resistência, a render-se. Uma vez assegurado o saque, o capitão voltou ao navio abandonado e dele tomou posse tranqüilamente. Aí ainda encontrou mercadorias de grande valor, como couro e moedas de cobre. A embarcação espanhola rumava para Santa Helena, mas um problema no leme e outras complicações obrigaram-na a procurar o porto de São Salvador.

Os capitães espanhóis que se encontravam no porto, como se pode bem imaginar, demonstraram grande interesse pelo caso e começaram as suas ameaças; creio que tinham a intenção de unir forças e reaver a presa do baleeiro. O mestre da presa, sem perda de tempo, veio pedir a nossa proteção. Disse-nos ele que, como já deveríamos ter ouvido da boca do oficial do Queen Indiamen, havia uma estreita relação e cooperação entre portugueses e espanhóis, cooperação pouco compatível com a suposta neutralidade pretendida pelos portugueses. Disse ainda que os navios ingleses seriam facilmente trapaceados se ficassem à espera de justiça e equidade nos portos da costa do Brasil.

O mestre da presa estava agora pronto para deixar o porto. Quanto aos espanhóis, com o movimento para cima e para baixo das nossas lanchas, eles acabaram por nos cumprimentar com uma polidez, se não notável, ao menos contrastante com as ofensas mútuas que havíamos trocado.

$\mathrm{Na}$ manhã seguinte, estivemos ocupados nos preparando para a visita de cerimônia ao governador. Antes de partirmos, o barco foi minuciosamente revistado pelos oficiais da alfândega e do barco-patrulha. Um crioulo negro de São Tomé, capitão a serviço de Portugal, recebeu-nos em terra, ofereceu seus serviços de intérprete - melhor dizendo, de espião - e conduziu-nos ao palácio. O crioulo trazia uma espécie de medalha pendurada em uma das abotoaduras, medalha que, segundo nos contou, tinha sido presente do príncipe do Brasil - o ornamento parecia ser para ele motivo de não pouco orgulho. Dei-me 
conta de que sua intenção ao expô-lo solenemente era impressionarnos com a sua importância.

Ao chegarmos ao palácio - assim é denominada a residência do vice-rei —, tivemos de aguardar um pouco para sermos honrados com uma audiência. Não sei dizer ao certo se a espera deveu-se às exigências do cerimonial português ou ao grande número de oficiais presentes na recepção matinal. Finalmente, conduziram-nos a uma sala de recepções onde se encontrava o governador. Dizem que Sua Excelência é um membro da família real e um típico português, tanto na aparência quanto nos hábitos. Ele vestia-se como um general em serviço e recebeu-nos com a tradicional cerimônia e fria arrogância da corte de Lisboa. Dirigindo-se a nós num excelente inglês, ele questionou-nos de uma maneira que indicava muita suspeição.

Nada pode ser mais cansativo do que o detalhado e zeloso interrogatório a que tivemos de nos submeter. Por mais de uma vez, Sua Excelência e seus oficiais examinaram e reexaminaram nossos mapas, diários, o diário de bordo e outros documentos. A decisão final veio confirmar os boatos que ouvíramos acerca da injusta preferência pelos nossos inimigos: enquanto os espanhóis carregavam e descarregavam mercadorias no porto tão deliberada e tranqüilamente como se estivessem no porto de Cadiz, nós, ingleses, segundo comunicou-nos Sua Excelência, tínhamos somente 4 dias para executar os reparos necessários no navio; expirado o prazo, deveríamos deixar o porto. Protestar era inútil, a ordem não admitia contestações.

Diversas ocorrências posteriores convenceram-me de que uma relação secreta, bastante prejudicial à Grã-Bretanha em tempos de guerra, era mantida entre portugueses e espanhóis. Tal relação é bastante contrária à posição de justa neutralidade, à qual, não tenho dúvidas, muitas embarcações do Brasil têm recorrido quando detidas pelos nossos cruzadores.

À tarde, recebemos a visita do nosso atirado lingüista crioulo, que vinha congratular-se conosco pela vitória obtida sobre os franceses ${ }^{14}$ por alguns navios ingleses que se encontravam na costa do Brasil. Ele insistiu muito para que fizéssemos um disparo de saudação, como era hábito entre os portugueses nessas ocasiões. A informação que nos tra- 
zia o crioulo, no entanto, era demasiado vaga e não a julgamos digna de um feu de joie.

A notícia, todavia, foi confirmada mais tarde. O Belliqueux e seu comboio tinham capturado duas fragatas francesas e dado caça a uma outra - todas pertencentes a uma esquadra que muito dano vinha causando ao comércio português.

Durante as visitas que fizemos à terra, tratamos de aproveitar da melhor maneira a estreita liberdade de que desfrutávamos e de manter os olhos bem atentos em busca daquilo que costuma atrair a atenção dos estrangeiros.

A cidade, que a natureza dividiu numa parte baixa e outra alta, é grande e populosa. A parte alta localiza-se no topo de uma elevação. Tem-se do lugar uma ampla vista da baía e do porto de Todos os Santos, vista arrematada, ao longe, pelo mar e pelas nuvens. Aí localizamse as residências do governador, dos oficiais civis e religiosos e dos principais comerciantes, enquanto a cidade baixa abriga, na sua maioria, as casas dos habitantes de ordem inferior, dos retalhistas, dos aventureiros e das pessoas que se dedicam aos ofícios mecânicos.

São Salvador, ao lado do Rio de Janeiro, é a cidade, do ponto de vista comercial, mais dinâmica da costa do Brasil. O comércio com a metrópole, levando-se em conta a indolência característica dos portugueses, é bastante vigoroso; o mesmo ocorre com o comércio com a costa da África, pois as minas de diamantes requerem um suplemento constante de negros e dinamizam o tráfico de homens. A bem da verdade, é preciso dizer que o trabalho dos negros é indispensável nas minas de diamantes, mas que, talvez, nem mesmo os diamantes, por mais inestimáveis que possam ser, devam ser comprados por um preço tão elevado.

Havia no estaleiro local um navio de 64 canhões em construção. O material utilizado era o pau-brasil, madeira bastante pesada para tal propósito, mas inquestionavelmente mais resistente do que qualquer carvalho europeu. O ferro, o alcatrão e o breu, pelo que entendi, vêm de Lisboa, pois a política da pátria mãe exige que quaisquer bens manufaturados sejam importados de lá... Tal restrição tinha algum sentido enquanto o número de artesãos e a riqueza disponível eram muito reduzidos para a abertura de manufaturas. Todavia, a indústria da colônia vem crescendo muito e a modernização da agricultura tem per- 
mitido aumentar o fornecimento de matérias primas; daí a manutenção dessa política egoísta tornar-se incompreensível.

Domingo, quando se comemorava uma importante festividade do calendário português, o capitão e eu aproveitamos a oportunidade para conhecer as igrejas do lugar. Pelo que vimos, tais construções fazem justiça tanto ao caráter da religião dos colonos quanto à riqueza da sua colônia: as igrejas são ricamente adornadas e os ornamentos das imagens pareceram-nos de grande valor. Pelo que vimos, também, e com alguma satisfação, embora não passemos de homens do mar, não há nenhum país no mundo onde a religião esteja tão em moda; as igrejas estão sempre cheias e são freqüentadas por todo tipo de gente, do mais humilde escravo ao próprio governador. A verdadeira piedade sempre toca de modo agradável e verdadeiro o coração de um homem, mesmo que ele seja protestante e, conseqüentemente, pouco simpático à sua santidade o papa. Foi impossível ver a referida cena com indiferença; na verdade, de tudo o que vimos entre os habitantes, foi o que mais contribuiu para que tivéssemos deles uma boa opinião.

Com grande dificuldade, conseguimos um assento na igreja principal. Meus olhos e os do capitão, de quando em quando, desviavamse do padre para uma Santa Virgem toda ornada de ouro e pedrarias, que trazia uma imagem do príncipe do Brasil, elegantemente vestido, na sua mão direita — talvez dando com isso a entender que o príncipe era um de seus mais destacados campeões e defensores - e ocupava um lugar de destaque na igreja. O pregador era o bispo da província, o segundo homem nesta parte do Brasil. O sermão, pelo que pude compreender através do meu intérprete, era eloqüente, tanto mais, quiçá, em virtude de o bispo ter consciência de sua alta posição social e das suas veneráveis funções. Ele dirigia-se sobretudo aos grandes, atacando com violência os seus vícios e as suas impiedades, num estilo vigoroso e livre, que um pregador mais humilde dificilmente adotaria.

Encerrada a cerimônia religiosa, a imagem da Santa Senhora, com seu assistente, o príncipe, foi levada em procissão pelas ruas da cidade, ao longo das quais era saudada por muitas senhoras que, adornadas com grinaldas e contas nas cabeças, encontravam-se nas janelas e balcões das casas. Um espetáculo teatral em nenhum sentido desagradá- 
vel, se aceitarmos que o entusiasmo por uma religião equivocada serve de desculpa para tais erros.

Depois de cruzar a cidade em todas as direções, a Santa Senhora é depositada numa outra igreja de porte e aí permanece esperando ou por uma nova festa, ou por uma tempestade. Mesmo aparentando desatenção, o capitão não viu esta pantomima sagrada com bons olhos; tamanha irreverência mereceu de sua parte uma dura reprimenda. Em muitas ruas da cidade havia, em um ou outro ponto destacado, imagens de santos padroeiros. Ao entardecer, a multidão comprime-se em torno desses santos entoando preces e ações de graça no tom monótono característico do cântico católico romano.

Tudo o que vimos convenceu-nos de que, em caso de ruptura entre os dois países, esta colônia será de grande valor para o Império Britânico. Ao longo dos anos, tem se mostrado evidente que ou a França ou a Inglaterra deverão tomar o Brasil sob sua tutela, pois uma nação débil e tão carente de estima na Europa como Portugal não pode, durante muito tempo, ter o monopólio sobre um país tão extenso, país que os portugueses mal conseguem explorar e defender. A França, caso se antecipe a nós - o que certamente pode acontecer, tendo em vista que a conquista é o princípio fundamental de um governo militar - , terá ganho um espólio mais do que suficiente para compensar a perda de Malta e do Egito. Para nós, uma nação comercial, tal aquisição traria mais vantagens, vantagens reais, do que todas as conquistas da França. Se os acontecimentos permitirem que o Brasil caia em nossas mãos, creio que haverá a possibilidade de garantir uma paz honrosa.

No dia previsto para partirmos, um outro navio espanhol, pesadamente carregado com cerca de 100.000 dólares e outras mercadorias de elevado valor, entrou no porto. Creiam que lamentamos muito não termos deixado o porto no dia anterior, pois tivemos de saudar esse rico navio espanhol, navio que veio livrá-los da encrenca de ter de levar o seu dinheiro para casa em embarcações portuguesas - suspeitávamos que tal manobra seria posta em prática.

É evidente que tem, de fato, havido uma política de estreita colaboração entre as duas coroas. Julgo-me, todavia, incapaz de avaliar se isto se deve à situação de vizinhança geográfica tanto entre suas possessões americanas quanto entre suas metrópoles, ou ao fato de terem um 
par nobile fratum. Estou, no entanto, certo de que tais ligações existem e estão, não me equivocaria em dizer, em pleno vigor nos dias que correm.

Ao expirar o quarto dia de nossa permanência no porto, expirou do mesmo modo a polidez dos portugueses, ou melhor, a sua não hostilidade. Recebemos a bordo a visita do mestre do porto com uma ordem do vice-rei para que não retornasse enquanto não tivéssemos deixado o lugar - ordem que obedecemos um pouco de má vontade. Devo salientar que a acolhida que recebemos não foi nem melhor nem pior do que a recebida por outras embarcações inglesas que freqüentam esta costa.

Fiquei bastante confuso ao analisar as razões que levam os portugueses a agirem de maneira tão pouco adequada a uma nação civilizada, sobretudo em relação aos naturais de um país ao qual, no panorama atual da Europa, eles devem a conservação do seu império. Esmereime em vão por descobrir o porquê de tal conduta, até que fui apresentado a um major em serviço, um veterano, bem mais experiente que seus companheiros oficiais. Ele explicou-me que as relações políticas entre a Inglaterra e Portugal, não raro, têm sido motivo de tensões entre os portugueses e seus vizinhos espanhóis. Desse modo, tornou-se um princípio de política externa atenuar o ciúme espanhol tratando os ingleses de maneira aparentemente — aparência que acaba por ser bastante real - severa $^{15}$.

FRANÇA, J. M. C. A British traveller in Bahia. História. São Paulo, v. 22, n. 2, pp. 229-240, 2003.

A BST RACT: In 1805 the British traveller John Turnbull published $A$ Voyage round the world in the years 1800,1801,1802, 1803, and 1804. In his diary Turnbull describes the environment he found in several places he visited during his journey, including Baía de Todos os Santos, where he stayed for five days in August, 1800. What follows is a fragment of Turnbull's journal - with an explanatory introduction - in which he presents his impressions about Brazil and it's relationship with Portugal during those years.

KEYWORDS: Salvador; navigation; British travellers. 


\section{NOTAS}

${ }^{1}$ Departamento de História - FHDSS - UNESP - CEP 14403-351 - Franca - SP.

${ }^{2}$ RODRIGUES, J. H. História da História do Brasil. Historiografia Colonial. $2^{\underline{a}}$ ed. São Paulo: Editora Nacional, 1979, p. XIX.

${ }^{3}$ TAUNAY, A. E. Visitantes do Brasil colonial. $2^{\underline{a}}$ ed. São Paulo: Companhia editora Nacional, 1938, p. 11.

${ }^{4}$ FRANÇA, J. M. C. Visões do Rio de Janeiro colonial. $2^{\underline{a}}$ ed. Rio de Janeiro: José Olympio Editora, 2000, pp. 253-259.

${ }^{5}$ LINDLEY, T. Narrativa de uma viagem ao Brasil. São Paulo: Companhia Editora Nacional, 1969.

${ }^{6}$ FRANÇA, J. M. C. Outras visões do Rio de Janeiro colonial. Rio de Janeiro: José Olympio Editora, 2001, pp. 258-286.

${ }^{7}$ KEITH, G. M. A Voyage to South America. London: Richard Phillips, 1810, pp. 16-18.

${ }^{8}$ HARO, M. A. P. de (Org.). Ilha de Santa Catarina. Relatos de viajantes estrangeiros nos séculos XVIII e XIX. Florianópolis: Editora da UFSC, Editora Lunardelli, $4^{\mathrm{a}}$ ed., 1996, pp. 137-145.

${ }^{9}$ FRANÇA, J. M. C. Outras visões..., pp. 297-309 e 311-320.

${ }^{10}$ TURNBULL, J. Voyage round the world, in the years 1800, 1801, 1802, 1803, and 1804; in which the author visited the principal islands in the Pacific ocean, and the English settlements of Port Jackson and Norfolk Island. London: Printed for R. Phillips by T. Gillet, 1805 .

${ }^{11}$ COSTA, H. J. da. Correio Brazilliense, ou Armazém Literário. São Paulo: Imprensa Oficial; Brasília: Correio Brasiliense, 2002, v. XVI, p. 141.

${ }^{12}$ TURNBULL, John, Op. cit., pp. 5-6.

${ }^{13}$ GUNTHER, L. The British community of 19th century Bahia: public and private lives. Oxford: University of Oxford Centre for Brazilian Studies, 2002, pp. 5-8 (Working Paper Series).

${ }^{14}$ Trata-se da esquadra francesa comandada pelo capitão Jean-François Landolphe. Acerca da passagem de Landolphe pelo Brasil, ver: FRANÇA, J. M. C. Visões..., pp. 253-259.

${ }^{15}$ A passagem acima foi extraída da primeira edição da obra: TURNBULL, J. Op. cit., pp. 8-18.

Artigo recebido em 04/2003. Aprovado em 07/2003. 